\title{
Predictive values of FAP and HGF for tumor angiogenesis and metastasis in colorectal cancer
}

\author{
T. H. MA, C. C. GAO, R. XIE, X. Z. YANG, W. J. DAI, J. L. ZHANG, W. YAN, S. N. WU* \\ Department of Gastroenterology, Huaian First People's Hospital, Nanjing Medical University, Huaian 223300, P.R. China \\ *Correspondence: shangnongwsn@163.com
}

Received December 14, 2016 / Accepted April 10, 2017

\begin{abstract}
This study aims to explore the correlation of hepatocyte growth factor (HGF) and fibroblast activation protein (FAP) expressions with the angiogenesis and metastasis in colorectal cancer (CRC). The immunohistochemical SABC method was used to detect HGF and FAP expressions in 127 CRC tissues, 51 colorectal polyp tissues and 28 normal tissues. HGF and FAP expressions in liver metastasis were detected using western blot to analyze the correlation of their expressions with lymph node metastasis and liver metastasis. Micro-vessel density (MVD) and clinic-pathologic information of CRC patients were recorded and analyzed. In CRC group, HGF and FAP expressions were greatly higher than those in normal group and colorectal polyps group $(P<0.05)$. Moreover, the positive rates of HGF and FAP expressions in lymph node metastasis were evidently higher than those in non-lymph node metastasis $(P<0.05)$. In liver metastasis group, HGF and FAP expressions were obviously higher than non-liver metastasis group $(P<0.05)$. CRC group had much more MVD in comparison with normal group and colorectal polyps group $(P<0.05)$. When compared with negative group, MVD was significantly higher than that in CRC tissue with positive HGF and FAP $(P<0.05)$. Spearman rank correlation analysis showed that HGF and FAP were in positive correlation with $\mathrm{MVD}(\mathrm{r}=0.542, P<0.001 ; \mathrm{r}=0.753, P<0.001)$. These results indicate that FAP and HGF play an important role in CRC angiogenesis, and their expression levels are valuable to predict CRC liver metastasis and lymph node metastasis.
\end{abstract}

Key words: colorectal cancer, fibroblast activation protein, hepatocyte growth factor, microvessel density, angiogenesis, metastasis

Colorectal cancer (CRC) ranks the top three frequently diagnosed cancers in the world for its high mortality [1]. Annually, there are more than 300,000 new cases in United States and Europe and more than 940,000 cases worldwide with 500,000 deaths from CRC [2]. Commonly, the CRC symptoms are changes in the stools, rectal bleeding or black stool, abdominal pain, fatigue, weight loss and anemia [3]. In addition, various lifestyle factors contribute to CRC incidence, including agricultural and industrial exposures (such as industrial materials, dusty environment, and pesticide), environmental pollution, obesity, food with high contents of polycholorinated biphenyl (PCB) and dichlorodiphenyltrichloroethane (DDT) [4]. Currently, plenty of serum and tumor markers have been identified, but as prognostic indicators they do not significantly improve the tumor staging of patients with stage II or III CRC for early detection of cancer recurrence, so it is urgent to find a new prognostic indicator [4].
Fibroblast activation protein (FAP), an inducible cell surface glycoprotein of 760 amino acids which belongs to the family of post-proline dipeptidyl aminopeptidase, was formerly named as F19 cell surface antigen since it was originally identified in cultured fibroblasts via using the monoclonal antibody F19 in 1986 [5]. Moreover, FAP is overexpressed by reactive stromal fibroblasts during epithelial-derived cancer growth, and during cancer expansion FAP digests extracellular matrix when tissues is remodeled, which may also promote an immune-tolerant tumor micro-environment [6]. Hepatocyte growth factor (HGF), also known as scatter factor (SF), is not only a multi-potent growth factor but also a mesenchymal(stromal-) derived factor playing a distinct role in growth, migration and morphogenesis of various cells like epithelial cell and hematopoietic cell, which exerts effects on tumor invasion and metastasis $[7,8]$. Several studies illustrated that HGF and its receptor c-Met were involved in the initiation, 
invasion and metastasis of some particular tumors, and what's more the activation and overexpression of autocrine HGF is a contributor to these tumors $[9,10]$. Otherwise, microvessel density (MVD) is often used as a surrogate measurement of angiogenesis in tumor models and pathological specimens [11]. As the indisputable relation has been noticed, that between MVD and quantifying angiogenesis, tumor differentiation by MVD could provide a critical prognostic approach towards the progression of this disease and its response to the drug therapy [12]. Currently, scanty studies pay attention to the correlation of FAP and HGF expressions with CRC vascular growth and metastasis. Therefore, this study aims to detect FAP and HDF expressions in liver metastasis in order to explore the correlation of their expressions with CRC angiogenesis, liver metastasis and lymph node metastasis.

\section{Materials and methods}

Ethics statement. This study has been approved by Ethics Committee of Huai'an First People's Hospital, Nanjing Medical University, and all patients have signed the written formed consent. All procedures in this study strictly complied with the guidelines and principles of the Declaration of Helsinki.

Study subjects. A total of 127 patients with pathologically proven CRC admitted in Huai'an First People's Hospital, Nanjing Medical University for surgery from June 2014 to December 2015 were enrolled in this study, including 68 males and 59 females with mean age of $57.20(57.20 \pm 9.50)$ years. Inclusive criteria: no history of diabetes and impaired glucose tolerance; no preoperative radiotherapy and chemotherapy; complete clinic-pathologic data. Exclusive criteria: preoperative drugs, chemotherapy, radiotherapy and immunotherapy; other parts of body suffering from malignant tumor; incomplete pathological data. According to standards issued by the International Association of Cancer (UICC) [13], all enrolled patients were classified by differentiation and Dukes' staging: 52 cases were classified as Dukes' stage A $+B$ and 75 cases as Dukes' stage C $+D ; 34$ cases of low differentiation, 41 cases of moderate differentiation and 52 cases of high differentiation; 51 cases of liver metastasis and 76 cases of no liver metastasis; 67 cases of lymph node metastasis and 60 cases of no lymph node metastasis. Meanwhile, 51 cases of colorectal polyps and 28 cases of normal colorectal mucosa (patients having other laparoscopic surgery) were selected as control group. There were no differences in gender and age among three groups, namely, normal colorectal mucosa group, colorectal polyp group and CRC group.

Specimen collection. Fresh CRC tissue from surgical removal, normal intestinal mucosa and colorectal polyp tissues were collected and saved quickly in liquid nitrogen for further experiments. A total of $3 \mathrm{ml}$ peripheral venous blood was taken before surgery to separate serum and be frozen at $-21^{\circ} \mathrm{C}$. Yeast two-hybrid was performed in FAP and HGF monomer to obtain the full gene fragment, and then plasmids were transfected into Escherichia coli, following by one-step
Triol method to extract FAP and HGF proteins for the preparation of polyclonal antibody. CRC tissue, normal intestinal mucosa and colorectal polyp tissue specimen were embedded by paraffin to prepare serial section of $3 \mu \mathrm{m}$.

Strept avidin-biotin complex (SABC) method. HGF and FAP expressions at protein level in three groups were detected by SABC method, in which phosphate buffer saline (PBS) was used as negative control instead of primary antibody and the given positive photo attached to SABC kit (Zhongshan Golden Bridge Biology Limited Company, Beijing, China) was used as positive control. All specimens were fixed in $4.0 \mathrm{~g} / \mathrm{L}$ paraformaldehyde (PA) for 24 hours, dehydrated and embedded in paraffin to prepare serial section of $3 \mu \mathrm{m}$, followed by 30 -min drying at $50^{\circ} \mathrm{C}$. Dewaxed section was incubated in $3 \% \mathrm{H}_{2} \mathrm{O}_{2}$ at room temperature for $20 \mathrm{~min}$ in order to block endogenous peroxidase activity. After antigen was retrieved in sodium citrate solution by microwave, the section was incubated in $50 \mathrm{ml} / \mathrm{L}$ normal goat serum at room temperature for $30 \mathrm{~min}$, followed by eliminating non-specificity staining by using closed charge point. The following procedures were carried out in accordance with the instructions of SABC kit. HGF and FAP monoclonal antibodies (United States Biological, Massachusetts, US) were diluted into 1:50 as primary antibody which was later added into section at $4^{\circ} \mathrm{C}$ overnight, following by adding biotin secondary antibody (1:100). Then the section was developed using diaminobenzidine (DAB) (Zhongshan Golden Bridge Biology Limited Company, Beijing, China), dehydrated, cleared by PBS and finally sealed.

HGF is mainly located in cytomembrane and cytoplasm of CRC cells, while FAP in stromal fibroblast around tumor cells. Additionally, their positive stains were yellow or brown particles in patchy distribution subsided in cytoplasm or cytomembrane. The tissue sections were graded based on cell count and staining intensity, and observed under highpowered microscope $(10 \times 40)$. We randomly selected 5 fields of each section, and 200 cells in each field (a total of 1,000 cells). The positive cells were defined as those showing brown stain in the cytoplasm or cell membrane. Based on the ratio of positive cells, we scored expressions as negative (1-10\% positive cells) (-), positive (11-50\%) (+) and strong positive $(>51 \%)(++)[14]$.

Western blotting. The liver tissues $(100 \mathrm{mg})$ were collected by grinding with liquid nitrogen, and then transferred to a $5 \mathrm{ml}$ centrifuge tube. The tube was added with $100 \mu \mathrm{l}$ radioimmuno precipitation assay (RIPA) lysis buffer (No. R0020. Beijing Solarbio Science and Technology Limited Company, Beijing, China) containing $1 \mathrm{mmol} / \mathrm{L}$ phenylmethylsulfonyl fluoride (PMSF). After centrifugal at $3000 \mathrm{r} / \mathrm{min}$, the cell was fully split. The liver tissues were placed in ice-cold $\left(4{ }^{\circ} \mathrm{C}\right.$ for $30 \mathrm{~min}$ ) and were centrifuged ( $12000 \mathrm{xg}$ for $4 \mathrm{~min}$ ), then the supernatant was aspirated for reserving at $-80^{\circ} \mathrm{C}$. A total of $50 \mu \mathrm{g}$ extracted protein was taken to perform sodium dodecyl sulfate polyacrylamide gel electrophoresis (SDS-PAGE), followed by transferring to nitrocellulose membrane (NC) using wet method. After sealed by milk, NC membrane carrying 

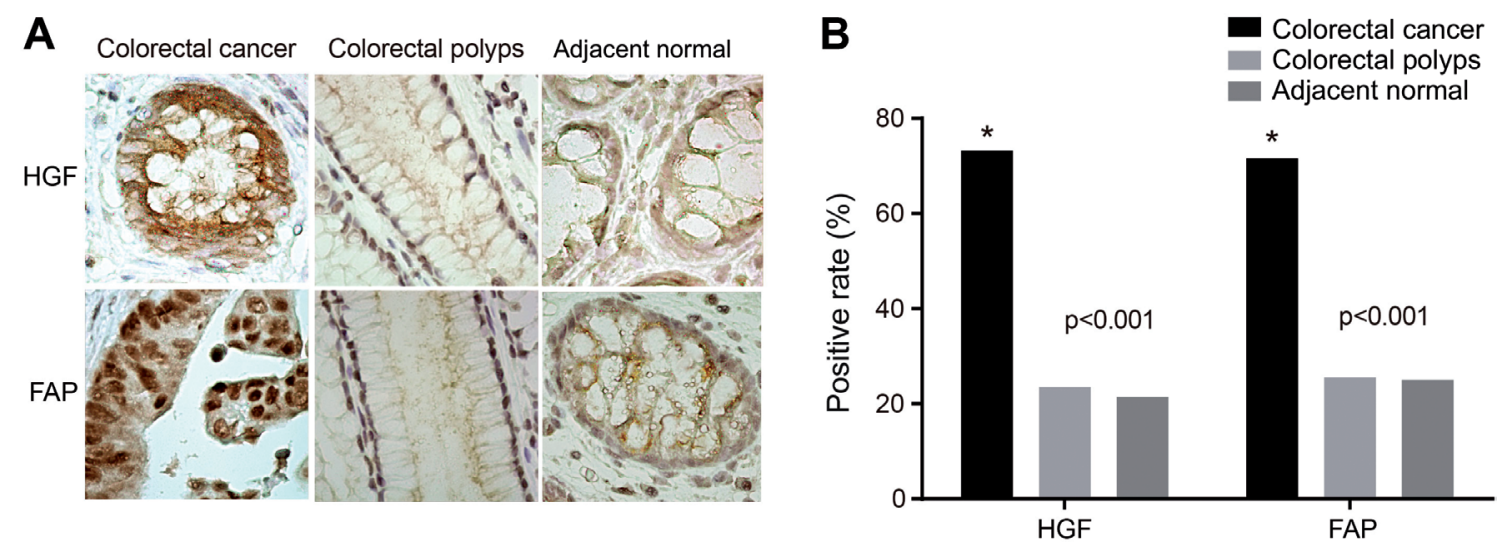

Figure 1. The immunohistochemical staining graphs (A) and histogram (B) of the protein expressions of HGF and FAP in the CRC, colorectal polyps and normal colorectal mucosa groups. Note: HGF, hepatocyte growth factor; FAP, fibroblast activation protein; CRC, colorectal cancer.

proteins were incubated with mouse anti-human monoclonal antibody of HGF and FAP (1:200) overnight and washed by tris buffered saline tween (TBST) for 4 times (10 min/time), following by 1-hour IRDyeTM 800DX-tagged goat anti-mouse immunoglobulin $\mathrm{G}(\mathrm{IgG})$ incubation in 1: 10000, TBST washing for 4 times and final developing. The above antibodies were purchased from Upstake Inc. New York, US. The protein brand quantification was analyzed and processed using Lab Works Image Acquisition and Analysis Software (UVP, Inc., Upland, CA, USA).

Blood vessels counting. Any endothelia cell or cell cluster stained brown which was significantly different from background was considered as single micro-vessel no matter cell cluster had cavity or not. But vessel in diameter of larger than 8 red blood cells or with thick muscle layer was not regarded as micro-vessel. The tissue section was observed under $100 \times$ microscopes to determine 3 regions of the highest microvessel density in tumor, followed by counting under $200 \times$ microscopes $\left(20 \times 10,0.739 \mathrm{~mm}^{2} /\right.$ field $)$ with the highest value as the micro-vessel count of this patient.

Statistical analysis. The statistical analysis was performed using the SPSS 18.0 "(IBM Corp., Armonk, NY, USA) software. Measurement data were expressed as mean \pm standard deviation (SD). The comparison of population mean between two groups was analyzed by independent sample $t$-test, and variance analysis was used in comparison among three groups. Enumeration data was expressed as ratio or percentage. Chisquare test was carried out to analyze positive expression ratio among groups and the corresponding data was analyzed by spearman rank correlation. $P<0.05$ was considered statistically significant.

\section{Results}

HGF and FAP expressions among three groups. HGF and FAP expressions at protein level were detected in CRC tissue, colorectal polyp tissue and normal colorectal mucosa tissue, but their positive expression rates were significantly different, HGF positive expression rate in CRC group was $73.23 \%$, while in colorectal polyps group and normal colorectal mucosa group, its positive expression rates were $23.53 \%$ and $21.43 \%$, suggesting that HGF positive expression rate and scores in CRC group were notably higher than those in the other groups (both $P<0.05$ ). Similarly, FAP positive expression rates in three groups were $71.65 \%, 25.49 \%$ and $25.00 \%$ respectively, and the score in CRC group was remarkably higher than that in colorectal polyps group and normal colorectal mucosa group $(P<0.05)$. There were no significant difference between colorectal polyps group and normal colorectal mucosa group $(P>0.05)$ (Figure 1).

Correlation of HGF and FAP expressions with clinicpathologic features of CRC patients. The expression levels of $\mathrm{HGF}$ and FAP in CRC were not associated with age, gender and tumor size $(P>0.05)$. HGF and FAP expressions were associated with Dukes' stage, that is, their positive rates in stage $\mathrm{C}+\mathrm{D}$ were higher than those in stage $\mathrm{A}+$ $\mathrm{B}$ (all $P<0.05)$. When compared with high differentiated CRC, HGF and FAP were highly expressed in low differentiated CRC (both $P<0.05$ ). The positive expression rates of HGF and FAP were significantly higher in lymph node metastasis tissue than those in tissue without metastasis (both $P<0.05$ ). Comparing with serosal invasion of CRC group, the positive expression rates of HGF and FAP were notably higher than those in group without invasion (both $P<0.05$ ) (Table 1).

HGF and FAP expressions in CRC patients with and without liver metastasis. The HGF expression quantity in liver metastasis group was greatly higher than that in patients without liver metastasis $(P<0.05)$. The comparison between two groups indicated that the primary tumor secretes HGF when tumor cells shed besides liver lesion releases HGF. The FAP expression quantity in liver metastasis group was evidently higher than that in non-liver metastasis group as well $(P<0.05)$ (Figure 2). 


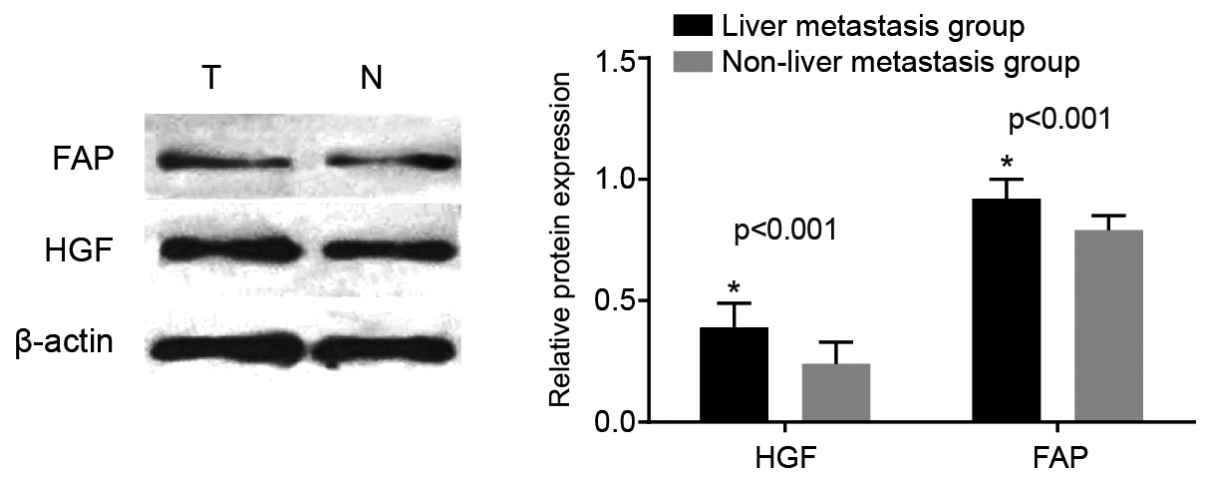

Figure 2. The protein expressions of HGF and FAP in T and $\mathrm{N}$ groups using Western blotting. Note: ${ }^{*}$ refers to compare with the $\mathrm{N}$ group, $P<0.05 ; \mathrm{HGF}$, hepatocyte growth factor; FAP, fibroblast activation protein; $\mathrm{T}$, the liver metastasis group; $\mathrm{N}$, the non-liver metastasis group.

Comparison of micro-vessel density (MVD) in CRC tissue, colorectal polyp tissue and normal colorectal tissue. The micro-vessel quantity differed in various tissues. Specially, micro-vessel was in concentrated distribution in CRC tissue, while fewer micro-vessels were detected in colorectal polyp and normal colorectal tissues, suggesting that MVD in CRC tissue was distinctly higher than that in colorectal polyp and normal colorectal tissues (all $P<$ 0.05). When compared with non-lymph node metastasis

Table 1. Correlation of HGF and FAP expression with clinico-pathologic characteristics of CRC patients

\begin{tabular}{lccccc}
\hline Characteristics & Cases $\begin{array}{c}\text { HGF positive } \\
\text { rate (\%) }\end{array}$ & $P$ value & $\begin{array}{c}\text { FAP positive } \\
\text { rate (\%) }\end{array}$ & $P$ value \\
\hline Age (years) & & 93 & 0.418 & 91 & 0.843 \\
$\quad$ ( 61 & $51(69.86)$ & & $53(72.60)$ & \\
$\quad>61$ & 54 & $42(77.78)$ & & $38(70.37)$ & \\
Gender & & & 0.842 & & 0.845 \\
$\quad$ Male & 68 & $49(72.06)$ & & $48(70.59)$ & \\
$\quad$ Female & 59 & $44(74.58)$ & & $43(72.88)$ & \\
Dukes' stage & & & 0.005 & & 0.046 \\
$\quad$ A + B & 52 & $31(59.62)$ & & $32(61.54)$ & \\
$\quad$ C + D & 75 & $62(82.67)$ & & $59(78.67)$ & \\
Differentiation & & & 0.022 & & 0 \\
$\quad$ High & 52 & $32(61.54)$ & & $29(55.77)$ & \\
$\quad$ Medium & 41 & $31(75.61)$ & & $30(73.17)$ & \\
$\quad$ Low & 34 & $30(88.24)$ & & $32(94.12)$ & \\
Invasion depth & & & $<0.001$ & & 0.005 \\
$\quad$ Serosal invasion & 58 & $51(87.93)$ & & $49(84.48)$ & \\
$\quad$ No serosal invasion & 69 & $42(60.87)$ & & $42(60.87)$ & \\
Tumor size & & & 0.688 & & 0.690 \\
$\quad \geq 5 \mathrm{~cm}$ & 75 & $56(74.67)$ & & $55(73.33)$ & \\
$\quad<5 \mathrm{~cm}$ & 52 & $37(71.15)$ & & $36(69.23)$ & \\
Lymph node metastasis & & & 0.002 & & 0.010 \\
$\quad$ Yes & 67 & $57(85.07)$ & & $55(82.09)$ & \\
$\quad$ No & 60 & $36(60.00)$ & & $36(60.00)$ & \\
\hline
\end{tabular}

Note: HGF, hepatocyte growth factor; FAP, fibroblast activation protein; CRC, colorectal cancer. group, MVD was higher in lymph node metastasis group $(P<0.05)$ (Figure 3).

Correlation of HGF and FAP expressions with CRC micro-angiogenesis. Spearman rank correlation (Figure 4) demonstrated that both HGF and FAP expressions were positively correlated with MVD (HGF: $\mathrm{r}=0.542, P<0.001$; FAP: $\mathrm{r}=0.753, P<0.001)$. MVD was gradually increased as HGF and FAP expression levels increased in CRC mesenchyme, indicating that HGF and FAP expressions in CRC tissue might facilitate tumor micro-angiogenesis.

\section{Discussion}

$\mathrm{CRC}$ is the second common cancer diagnosed and the third leading cause of cancer death worldwide, which poses more and more burden on Asia recently [4]. Although several protein and gene markers provide prognostic information of CRC so far [15], there were scanty researches on the correlation of FAP and HGF proteins with CRC

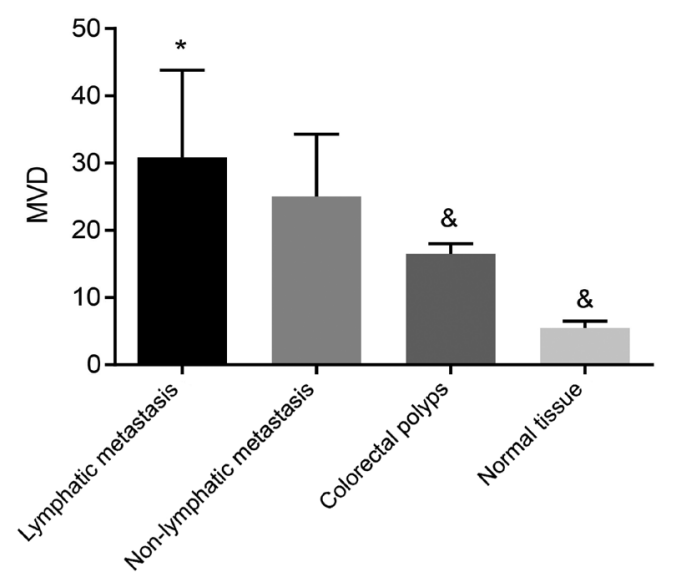

Figure 3. The distribution of MVD in the colorectal polyps, normal colorectal mucosa, non-lymph node metastasis and lymphatic metastasis groups. Note: ${ }^{\star}$ refers to compare with non-lymph node metastasis, $P<0.05$; \& refers to compare with CRC tissue, $P<0.05$; MVD, microvessel density. 

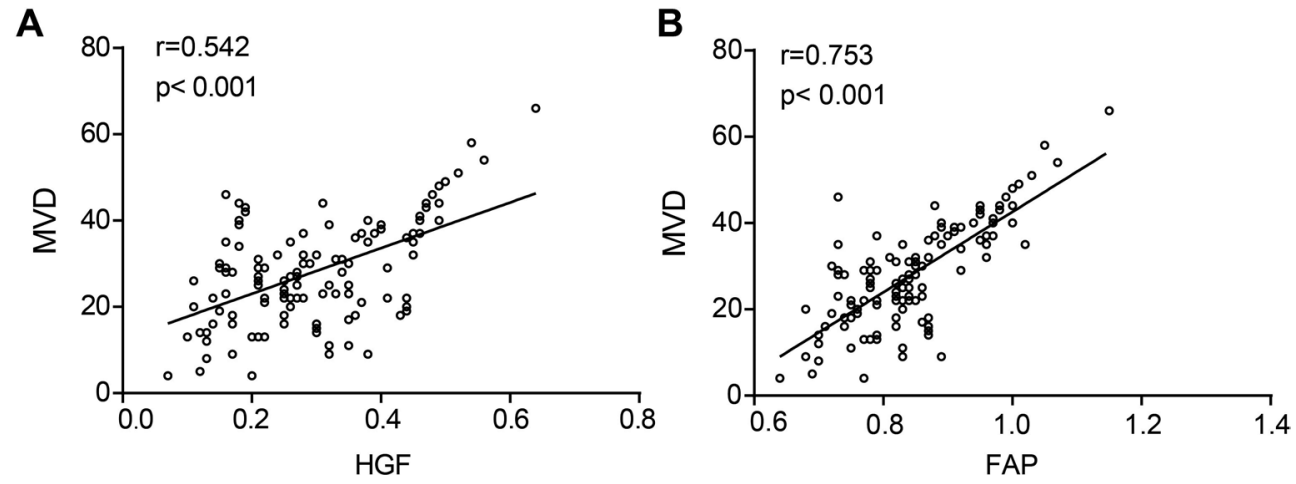

Figure 4. The correlations of HGF and FAP protein expressions with MVD.

Note: A, The correlation of HGF protein expression with MVD; B, The correlation of FAP protein expression with MVD; MVD, microvessel density; HGF, hepatocyte growth factor; FAP, fibroblast activation protein.

angiogenesis and metastasis, which is of great significance to be explored.

This study found that HGF and FAP expressions at protein level were notably higher in CRC tissue than those in colorectal polyp and normal colorectal tissues. HGF is an effector of cells expressing the Met tyrosine kinase receptor besides a multifunctional heterodimeric polypeptide produced by mesenchymal cells [16]. Additionally, HGF is involved in the development of malignancy, especially invasive growth, metastasis and drug resistance [17]. Besides, HGF-Met pathway is critical for the cancer stem cell scattering and maintenance, which becomes the molecular target for anticancer therapy [18]. Furthermore, HGF and MET are co-expressed in the CRC micro-environment, and the increased expression of HGF is closely correlated with advanced stage disease and poor prognosis [19]. Recently, FAP expression was detected in many cancer cells, indicating that FAP is a vital marker of malignancy $[20,21]$. In addition, FAP is mainly expressed in tumor stromal fibroblasts rather than in normal adult tissue and epithelial damage caused by benign and precancerous lesions [22]. Reasonably, our results showed that FAP expression in CRC tissue was higher when compared with colorectal polyp and normal groups. In this study, it has been discovered that in lymph node and liver metastasis groups, the positive rates of HGF and FAP were distinctly higher than those in non-metastasis groups. The ligand of c-MET is HGF that implicates c-MET in the development, progression and metastasis of cancer via acting on c-MET in tumor cells to activate downstream signaling pathway, and high c-MET expression has been detected in CRC which is associated with liver metastasis, suggesting that c-MET can be the potential marker of liver metastasis [23]. The up-regulation of HGF facilitates tumor cells invasion into lymph vessels, namely lymph node metastasis, via increasing the surface area of tumor cells on lymph vessels and giving new lymph vessel thinner wall, larger lumen and better permeability by inducing proliferation of lymphatic endothelial and lymph vessels directly or indirectly, which proves that HGF was in positive correlation with lymph node metastasis of CRC [24]. Given that FAP is a serine protease having both dipeptidyl peptidase (DPP) and collagenase activity, FAP proteolytic activity degrading extracellular matrix confers an advantage for tumor cells to shed from primary site, which promotes tumor metastasis and invasion [25]. Moreover, it was found that the high expression of FAP was significantly correlated with tumor invasive depth and lymph node metastasis in some specific cancer tissues [26].

In this study, we found MVD in CRC tissue was in concentrated distribution, while MVD was lower in colorectal polyp and normal colorectal tissues, and was higher in CRC group. Additionally HGF and FAP expressions were positively correlated with MVD, revealing that HGF and FAP expressions promote tumor micro-angiogenesis in CRC tissues. Immunohistochemically, the degree of MVD is thought to be a critical factor which influences tumor metastasis and prognosis in various human cancers [27]. It was demonstrated that the MVD in invasive micropapillary carcinoma (IMPC) group was significantly higher than that in invasive ductal carcinoma (IDC) [28]. The up-regulated expression of caveolin-1 and MVD is connected with and a worse prognosis and metastasis in clear cell renal cell carcinoma (RCC) [29].HGF activates tumor mechanism to generate new tumor vessel for tumor growth and metastasis, and destroys intercellular junctions to improve tumor metastasis and invasion [30, 31]. In addition, there are no FAP detected in adult liver, and FAP provides the signal for epithelial cells and secretes in tumor stroma to change extracellular matrix, leading to accelerate angiogenesis and tumor exacerbation, which is considered as a critical factor for tumor occurrence, development and scattering.

This study explored the correlation of FAP and HGF protein expressions with CRC angiogenesis and metastasis. We also found that FAP and HGF act as a vital role in CRC angiogenesis and that their expression levels are valuable to predict liver metastasis and lymph node metastasis. However, there are limitations in this study, that is, the mechanism of FAP and HGF in CRC occurrence, development and prognosis is 
still unclear, which needs more clinical evidences to confirm this conclusion.

Acknowledgments: We would like to acknowledge the helpful comments on this paper received from our reviewers.

\section{References}

[1] ATKIN WS, EDWARDS R, KRALJ-HANS I, WOOLDRAGE $\mathrm{K}, \mathrm{HART}$ AR et al. Once-only flexible sigmoidoscopy screening in prevention of colorectal cancer: a multicentre randomised controlled trial. Lancet 2010; 375: 1624-1633 https://doi.org/10.1016/S0140-6736(10)60551-X

[2] CAPPELLANI A, DI VITA M, ZANGHI A, VEROUX P, CAVALLARO A et al. Biological and clinical markers in colorectal cancer: state of the art. Front Biosci (Schol Ed). 2010; 2: 422-431. https://doi.org/10.2741/s75

[3] TAO K, GAO J, WANG G. [Clinicopathological characteristics of colorectal carcinoma in the elderly]. Zhonghua Wei Chang Wai Ke Za Zhi. 2016; 19:495-498.

[4] LO AC, SOLIMAN AS, KHALED HM, ABOELYAZID A, GREENSON JK. Lifestyle, occupational, and reproductive factors and risk of colorectal cancer. Dis Colon Rectum 2010; 53 : 830-837. https://doi.org/10.1007/DCR.0b013e3181d320b1

[5] LIU R, LI H, LIU L, YU J, REN X. Fibroblast activation protein: A potential therapeutic target in cancer. Cancer Biol Ther 2012; 13: 123-129 https://doi.org/10.4161/cbt.13.3.18696

[6] CHRISTIANSEN VJ, JACKSON KW, LEE KN, DOWNS TD, MCKEE PA. Targeting inhibition of fibroblast activation protein-alpha and prolyl oligopeptidase activities on cells common to metastatic tumor microenvironments. Neoplasia 2013; 15: 348-358. https://doi.org/10.1593/neo.121850

[7] NAKAMURA T, MIZUNO S. The discovery of hepatocyte growth factor (HGF) and its significance for cell biology, life sciences and clinical medicine. Proc Jpn Acad Ser B Phys Biol Sci 2010; 86: 588-610. https://doi.org/10.2183/pjab.86.588

[8] DATE K, MATSUMOTO K, KUBA K, SHIMURA H, TANAKA $M$ et al. Inhibition of tumor growth and invasion by a four-kringle antagonist (HGF/NK4) for hepatocyte growth factor. Oncogene 1998; 17: 3045-3054. https://doi. org/10.1038/sj.onc. 1202231

[9] MA J, DEFRANCES MC, ZOU C, JOHNSON C, FERRELL $\mathrm{R}$ et al. Somatic mutation and functional polymorphism of a novel regulatory element in the HGF gene promoter causes its aberrant expression in human breast cancer. J Clin Invest 2009; 119: 478-491. 0 https://doi.org/10.1172/JCI36640

[10] KIM KJ, SU Y-C, WANG L. Monoclonal antibodies to hepatocyte growth factor. Patent US7220410 (B2), 2007

[11] SHIVAKUMAR S, PRABHAKAR BT, JAYASHREE K, RAJAN MG, SALIMATH BP. Evaluation of serum vascular endothelial growth factor (vegf) and microvessel density (mvd) as prognostic indicators in carcinoma breast. J Cancer Res Clin Oncol 2009; 135: 627-636. https://doi.org/10.1007/s00432008-0497-9

[12] AL-GHORBANI M, VIGNESHWARAN V, RANGANATHA VL, PRABHAKAR BT, KHANUM SA. Synthesis of oxadiazole-morpholine derivatives and manifestation of the repressed cd31 microvessel density (mvd) as tumoral angiogenic parameters in dalton's lymphoma. Bioorg Chem 2015; 60: 136-146. https://doi.org/10.1016/j.bioorg.2015.04.008

[13] AKKOCA AN, YANIK S, OZDEMIR ZT, CIHAN FG, SAYAR $S$ et al. TNM and Modified Dukes staging along with the demographic characteristics of patients with colorectal carcinoma. Int J Clin Exp Med 2014; 7: 2828-2835.

[14] TROVATO M, VITARELli E, GROSSO M, ALESCI S, BENVENGA S et al. Immunohistochemical expression of hgf, c-met and transcription factor stat 3 in colorectal tumors. Eur J Histochem 2004; 48: 291-297.

[15] VAN SCHAEYBROECK S, ALLEN WL, TURKINGTON RC, JOHNSTON PG. Implementing prognostic and predictive biomarkers in CRC clinical trials. Nat Rev Clin Oncol 2011; 8: 222-232. https://doi.org/10.1038/nrclinonc.2011.15

[16] CAO B, SU Y, OSKARSSON M, ZHAO P, KORT EJ et al. Neutralizing monoclonal antibodies to hepatocyte growth factor/scatter factor (HGF/SF) display antitumor activity in animal models. Proc Natl Acad Sci U S A 2001; 98: 7443-7448. https://doi.org/10.1073/pnas.131200498

[17] MICHIELI P, BASILICO C, PENNACCHIETTI S, MAFFÈ A, TAMAGNONE L et al. Mutant Met-mediated transformation is ligand-dependent and can be inhibited by HGF antagonists. Oncogene 1999; 18: 5221-5231. https://doi.org/10.1038/ sj.onc. 1202899

[18] MIZUNO S, NAKAMURA T. HGF-MET cascade, a key target for inhibiting cancer metastasis: the impact of NK4 discovery on cancer biology and therapeutics. Int J Mol Sci 2013; 14: 888-919. https://doi.org/10.3390/ijms14010888

[19] LISKA D, CHEN CT, BACHLEITNER-HOFMANN T, CHRISTENSEN JG, WEISER MR. HGF rescues colorectal cancer cells from EGFR inhibition via MET activation. Clin Cancer Res 2011; 17: 472-482. https://doi.org/10.1158/10780432.CCR-10-0568

[20] EL KHOURY J, KURBAN M, KIBBI AG, ABBAS O. Fibroblastactivation protein: valuable marker of cutaneous epithelial malignancy. Arch Dermatol Res 2014; 306: 359-365. https:// doi.org/10.1007/s00403-014-1456-8

[21] ABBAS O, RICHARDS JE, MAHALINGAM M. Fibroblastactivation protein: a single marker that confidently differentiates morpheaform/infiltrative basal cell carcinoma from desmoplastic trichoepithelioma. Mod Pathol 2010;23: 1535-1543. https:// doi.org/10.1038/modpathol.2010.142

[22] LO PC, CHEN J, STEFFLOVA K, WARREN MS, NAVAB R et al. Photodynamic molecular beacon triggered by fibroblast activation protein on cancer-associated fibroblasts for diagnosis and treatment of epithelial cancers. J Med Chem 2009; 52: 358-368 https://doi.org/10.1021/jm801052f

[23] JIA Y, DAI G, WANG J, GAO X, ZHAO Z et al. c-MET inhibition enhances the response of the colorectal cancer cells to irradiation in vitro and in vivo. Oncol Lett 2016; 11 : 2879-2885. https://doi.org/10.3892/ol.2016.4303

[24] FAZEKAS K, CSUKA O, KOVES I, RASO E, TIMAR J. Experimental and clinicopathologic studies on the function of the HGF receptor in human colon cancer metastasis. Clin Exp Metastasis 2000; 18: 639-649. https://doi. org/10.1023/A:1013136303880 
[25 CHENG JD, DUNBRACK RL JR, VALIANOU M, ROGATKO A, ALPAUGH RK et al. Promotion of tumor growth by murine fibroblast activation protein, a serine protease, in an animal model. Cancer Res 2002; 62: 4767-4772.

[26] WEN Y, WANG CT, MA TT, LI ZY, ZHOU LN et al. Immunotherapy targeting fibroblast activation protein inhibits tumor growth and increases survival in a murine colon cancer model. Cancer Sci 2010; 101: 2325-2332. https://doi. org/10.1111/j.1349-7006.2010.01695.x

[27] IORDACHE S, SAFTOIU A, GEORGESCU CV, RAMBOIU S, GHEONEA DI et al. Vascular endothelial growth factor expression and microvessel density--two useful tools for the assessment of prognosis and survival in gastric cancer patients. J Gastrointestin Liver Dis 2010; 19: 135-139.

[28] LI W, YANG D, WANG S, GUO X, LANG R et al. Increased expression of cd146 and microvessel density ( $\mathrm{mvd}$ ) in invasive micropapillary carcinoma of the breast: Comparative study with invasive ductal carcinoma-not otherwise specified.
Pathol Res Pract 2011; 207: 739-746. https://doi.org/10.1016/j. prp.2011.09.009

[29] JOO HJ, OH DK, KIM YS, LEE KB, KIM SJ. Increased expression of caveolin-1 and microvessel density correlates with metastasis and poor prognosis in clear cell renal cell carcinoma. BJU Int 2004; 93: 291-296. https://doi. org/10.1111/j.1464-410X.2004.04604.X

[30] CHAU GY, LUI WY, CHI CW, CHAU YP, LI AF et al. Significance of serum hepatocyte growth factor levels in patients with hepatocellular carcinoma undergoing hepatic resection. Eur J Surg Oncol 2008; 34: 333-338. https://doi.org/10.1016/j. ejso.2006.12.007

[31] LI Z, YOU K, LI J, WANG Y, XU H et al. Madecassoside suppresses proliferation and invasiveness of HGF-induced human hepatocellular carcinoma cells via PKC-cMET-ERK1/2-COX2-PGE2 pathway. Int Immunopharmacol 2016; 33: 24-32. https://doi.org/10.1016/j.intimp.2016.01.027 